\title{
Comparison between high-flow nasal oxygen cannula and conventional oxygen therapy after extubation in pediatric intensive care unit
}

\author{
Başak Akyıldız ${ }^{1}$, Sedat Öztürk ${ }^{1}$, Nazan Ülgen-Tekerek ${ }^{1}$, Selim Doğanay ${ }^{2}$, Süreyya Burcu Görkem² \\ Departments of ${ }^{1}$ Pediatric Intensive Care and ${ }^{2}$ Radiology, Erciyes University Faculty of Medicine, Kayseri, Turkey. \\ E-mail: basaknurbesra@gmail.com \\ Received: 26th May 2017, Revised: 12th July 2017, 7th August 2017, Accepted: 30th August 2017
}

SUMMARY: Akyıldız B, Öztürk S, Ülgen-Tekerek N, Doğanay S, Görkem SB. Comparison between high-flow nasal oxygen cannula and conventional oxygen therapy after extubation in pediatric intensive care unit. Turk J Pediatr 2018; 60: 126-133.

The aim of this study was to compare the efficiency, safety, and outcomes of the high-flow nasal oxygen cannula (HFNC) and conventional oxygen therapy (COT) after extubation in children. A randomized controlled trial was conducted in a 13 bed pediatric intensive care unit. One-hundred children who underwent extubation were eligible for the study. Patients were divided into HFNC $(n=50)$ and COT $(n=50)$ groups. Basal variables including heart rate (HR), noninvasive blood pressure, respiratory rate (RR), $\mathrm{SpO}_{2}, \mathrm{SpO}_{2} / \mathrm{FiO}_{2}$ (SF) ratio, and end tidal $\mathrm{CO}_{2}\left(\mathrm{EtCO}_{2}\right)$ were obtained initially and recorded at 15,30, and 45 minutes and at 1, 6, 12 hours, 24 and 48 hours after extubation. SF ratio and $\mathrm{SpO}_{2}$ increased during the first hour in the HFNC group ( $\mathrm{p}=0.005$ and $\mathrm{p}=0.03$, respectively). $\mathrm{HR}$ and $\mathrm{RR}$ decreased during follow-up in the HFNC group $(p=0.001$ and $p=0.048$, respectively). There was no statistically significant difference for $\mathrm{PCO}_{2}$ after extubation between the two groups. $\mathrm{PCO}_{2}(\mathrm{p}=0.008)$ and $\mathrm{EtCO}_{2}(\mathrm{p}=0.018)$ values at 24 -h were different between two groups. At follow-up, HR decreased only in the HFNC group $(p=0.001)$ and was different at 12 and 48 hours $(p=0.047$ and $p=0.01$, respectively). Initial modified radiologic atelectasis scores (m-RAS) were higher for the HFNC group and decreased steadily $(p=0.001)$. Extubation failure rates were $4 \%$ and $22 \%$ for the HFNC and COT groups, respectively $(p=0.007)$. In conclusion, HFNC is better than COT, especially for the restoration of the respiratory and radiologic parameters. Although more expensive, the use of HFNC may have more advantages to reduce the risk of extubation failure in critically ill children compared with COT.

Key words: children, conventional oxygen therapy, extubation, high-flow nasal oxygen cannula.

High-flow devices include venturi masks and large-volume aerosol systems, high-humidity face tents and high-humidity tracheostomy collars. High-flow nasal cannula oxygen cannula (HFNC) is a new technological device used in high-flow systems. It consists of an air-oxygen blender that generates flow between $2-70 \mathrm{~L} /$ min and a heated humidification system. ${ }^{1,2}$ This may provide several advantages such as reducing the work of breathing, washing out pharyngeal dead space, reducing nasopharyngeal resistance, creating some positive end expiratory pressure, creating constant $\mathrm{FiO}_{2}$, and facilitating secretion clearance from humidified gas. ${ }^{1,2}$ HFNC demonstrated beneficial effects in many respiratory failure settings. ${ }^{1-4}$ Although the use of HFNC is increasingly popular for noninvasive support in neonatal and adult intensive care units, there are limited studies indicating beneficial effects of HFNC during

This manuscript was presented at the 13th Congress of Child Emergency and Intensive Care, 5 $5^{\text {th }}$ October 2016, Izmir, Turkey; and was published in abstract form in the proceedings of the Congress. 
the postextubation period in the literature. ${ }^{5-8}$ We aimed to compare the efficiency, safety and outcome of HFNC and conventional oxygen therapy (COT) after extubation period in critically ill children.

\section{Material and Methods}

A randomized controlled study was performed in a 13 bed pediatric intensive care unit during September 2014 and February 2016. The study was approved by the Ethics Committee of Erciyes University Medical Faculty. Consent was obtained from at least one parent or legal guardian before enrollment.

One hundred and six children who underwent on extubation process were included prospectively in the study. Six patients were excluded from the study. Exclusion criteria were: intubation for less than 24 hours, spontaneous breathing trial (SBT) failure, age older than 18 years and younger than 1 months, diaphragmatic hernia or paralysis, cyanotic congenital heart disease with unrepaired or palliated right to left intracardiac shunt, and presence of a tracheostomy tube. After successful SBT, one-hundred patients were extubated. Patients were divided into two groups by simple randomization: HFNC $(\mathrm{n}=50)$ and $\mathrm{COT}(\mathrm{n}=50)$.

\section{Outcomes}

The primary outcomes were the changes of respiratory, hemodynamic and radiologic parameters in both groups. Basal variables including heart rate, noninvasive blood pressure, respiratory rate (RR), $\mathrm{SpO}_{2}, \mathrm{SpO}_{2} / \mathrm{FiO}_{2}(\mathrm{SF})$ ratio, and end tidal $\mathrm{CO}_{2}\left(\mathrm{EtCO}_{2}\right)$ were initially obtained. These variables were also recorded at 15, 30 and 45 minutes; and at 1, 6, 12, 24 and 48 hours in the immediate-extubation period. Modified radiological atelectasis score (m-RAS) were recorded at baseline and at 24 and 48 hours after extubation period.

Secondary outcomes were reintubation rate and reasons of reintubation. In the follow-up, the decision of reintubation was made by the treating clinician. The decision to reintubate was based via the most significant factors recorded such as hypoxemia, presence of copious secretions, signs of respiratory-muscle fatigue, decreased level of consciousness (fall in GCS of more than 2), hypotension despite adequate volume and vasopressor therapy, etc. ${ }^{9}$

\section{Device description}

Vital signs including $\mathrm{SpO}_{2}$, heart rate, systolic blood pressure and diastolic blood pressure data were recorded using GE 650 monitors.

The HFNC system (Optiflow, Fischer\&Paykel Healthcare) is a humidifier with an integrated flow generator that delivers high flow and warmed respiratory gases to spontaneously breathe through a variety of patients interfaces. After applying the appropriate nasal cannula and circuit tubing with a Fisher and Paykel ${ }^{\circledR}$ MR850 humidifier, we used a flow rate of 1 $\mathrm{L} / \mathrm{min} / \mathrm{kg}$ and $\mathrm{FiO}_{2}$ of $40 \%$ and if there was no clinical improvement we titrated flow up to $2 \mathrm{~L} / \mathrm{kg} / \mathrm{min}$ or a maximum $25 \mathrm{~L} / \mathrm{min}$ and $\mathrm{FiO}_{2}$ to maintain $\mathrm{SpO}_{2} \geq 92 \%$.

The Capnostream 20 system was used to monitor $\mathrm{EtCO}_{2}$ levels via the Filter Line $\mathrm{H}$ set $\mathrm{CO}_{2}$ sampling line and airway adapter and also the respiratory pattern after extubation.

COT was delivered by either nasal cannula or a simple face mask with the same target $\mathrm{SpO}_{2}$. In this group, oxygen was delivered with a flow meter from wall oxygen and humidification with a closed sterile water system at room temperature. Similar to the HFNC group $\mathrm{FiO}_{2}$ and flow were titrated to maintain $\mathrm{SpO}_{2} \geq 92 \%$.

$\mathrm{SpO}_{2} / \mathrm{FiO}_{2}$ (SF) ratio was directly calculated in the HFNC group according to recorded $\mathrm{SpO}_{2}$ and $\mathrm{FiO}_{2}$ during the time interval. In the COT group, $\mathrm{SpO}_{2}$ was recorded directly during the time interval. To estimate $\mathrm{FiO}_{2}$ during oxygen therapy via a nasal cannula and simple face mask, we calculated $\mathrm{FiO}_{2}$ using a previously published formula. ${ }^{10}$

Demographic data including age, gender, initial diagnosis, PRISM III, PELOD, mechanical ventilation indication and duration, and admission diagnosis were also evaluated.

\section{Procedures}

Spontaneous breathing trial: The eligibility criteria for participation in SBT are as follows:

1. Improvement or resolution of underlying disease during follow-up.

2. Adequate gas exchange indicated by a $\mathrm{PaO}_{2}$ level greater than $60 \mathrm{mmHg}$ while breathing with $\mathrm{FiO}_{2}$ concentration of 0.4 or lower with no need for increased ventilator support during the previous 24 hours. 
3. Core body temperature lower than $38.5^{\circ} \mathrm{C}$.

4. Alert mental status after removal of sedative agents.

5. No clinical need for increased ventilator support during the previous 24 hours.

6. No need for vasoactive agents except for low-dose dopamine $(5 \mu \mathrm{g} / \mathrm{kg} / \mathrm{min}$; patients who received milrinone, epoprostenol, or nitroprusside were considered for extubation if other criteria were met)

7. Able to swallow secretions.

Patients underwent a 2-hours trial of spontaneous breathing with pressure support ventilation. Pressure support was set according to endotracheal tube (ETT) size $(3.0-3.5 \mathrm{~mm}$ -pressure support of $10 \mathrm{cmH}_{2} \mathrm{O}, 4.0-4.5 \mathrm{~mm}$ pressure support of $8 \mathrm{~cm} \mathrm{H} \mathrm{H}_{2} \mathrm{O}$, and $5.0 \mathrm{~mm}$ pressure support of $6 \mathrm{cmH}_{2} \mathrm{O}$ ). At the end of the SBT, exhaled tidal volume $>5 \mathrm{ml} / \mathrm{kg}$ body weight, $\mathrm{SpO} 2>95 \%$ and respiratory rate in acceptable range for age were considered successful completion of the SBT. Extubation failure was defined as the needing reintubation within 48 hours of extubation. ${ }^{11,12}$ In both study groups, patients were reintubated according to selection criteria.

\section{Atelectasis scoring}

Chest radiographs were scored using a m-RAS system by two pediatric radiologists at baseline and at 24 and 48 hours immediate-extubation period. This scoring system was first referenced by Parke et al. in 2014. ${ }^{13}$ The pediatric radiologists who assessed the m-RAS system were blinded to treatment allocations.

\section{Statistical analysis}

Numerical variables were expressed as mean \pm SD or median (minimum, maximum) when appropriate. Comparisons between groups for data with a normal distribution were performed using Student's t-test, and the comparisons between groups for data without a normal distribution were performed using the Mann-Whitney $U$ test. Changes over time of the recorded variables were evaluated by mixed model linear analysis due to missing values for repeated measurements. Categorical variables were compared using $\mathrm{x}^{2}$ test. A $\mathrm{p}$ value $<0.05$ was considered significant.

\section{Results}

One-hundred children were analyzed. The mean age was $27 \pm 19.95$ months for the HFNC group and $52.9 \pm 34.4$ months for the COT group $(\mathrm{p}=0.706) ; 49$ patients (49\%) were boys. There were no significant differences in PRISM III, PELOD scores, mechanical ventilation duration, and diagnosis at admission between two groups. Baseline characteristics and demographic data of the patients were summarized in Table I.

Table I. Baseline Characteristics of the Patients.

\begin{tabular}{lccc}
\hline \multirow{2}{*}{ Variable } & \multicolumn{2}{c}{ Groups } & $\mathrm{p}$ \\
\cline { 2 - 3 } Age, months & HFNC & COT & 0.706 \\
Male, N (\%) & $27 \pm 19.95$ & $52.9 \pm 34.4$ & 0.548 \\
PRISM III & $26(52 \%)$ & $23(46 \%)$ & 0.72 \\
PELOD & $17.78 \pm 6.66$ & $18.3 \pm 7.23$ & 0.981 \\
Duration of MV, days & $15.9 \pm 6.9$ & $16.4 \pm 7$ & 0.225 \\
Reintubation, N (\%) & $5(3-10)$ & $6(2-10)$ & 0.007 \\
Reintubation time, hours & $2(4)$ & $11(22)$ & 0.066 \\
Diagnosis at admission, N (\%) & $16(10-24)$ & $12(6-24)$ & \\
Respiratory & & & \\
Infectious & $25(50)$ & $30(60)$ & 0.349 \\
Neurologic & $13(26)$ & $10(20)$ & \\
Cardiologic & $7(14)$ & $3(6)$ & \\
Others & $5(10)$ & $2(10)$ & \\
\hline
\end{tabular}

COT: conventional oxygen therapy; HFNC: high-flow nasal oxygen cannula; MV: mechanical ventilation; PELOD: Pediatric Logistic Organ Dysfunction Score; PRISM III: Pediatric Risk of Mortality Score. 


\section{Primary outcomes}

$\mathrm{SpO}_{2}$ values were statistically higher starting at 60 minutes in the HFNC groups, $(\mathrm{p}=0.05)$ (Table II). In the HFNC group, SF values were statistically higher starting at 45 minutes and during intergroup comparison $(\mathrm{p}=0.005)$. Compared to baseline values, SF values were lower in the COT group and higher in the HFNC group at the end of the study $(\mathrm{p}=0.009$ and $\mathrm{p}<0.001)$. There were no statistically significant differences in $\mathrm{PCO}_{2}$ during the extubation period in both groups $(\mathrm{p}=0.300$ and $\mathrm{p}=0.357) . \mathrm{PCO}_{2}$ and $\mathrm{EtCO}_{2}$ at 24-hour were significantly lower in the HFNC group, compared to COT group $(\mathrm{p}=0.008$ and $\mathrm{p}=0.018$, respectively). EtCO $\mathrm{CH}_{2}$ was statistically significant lower during intergroup comparisons in the HFNC group $(p=0.018)$. During the follow-up, heart rate decreased only in the HFNC group

Table II. Clinical and Laboratory Data After Extubation Period.

\begin{tabular}{|c|c|c|c|c|c|c|c|c|c|c|}
\hline \multirow[b]{2}{*}{ Variables } & \multicolumn{9}{|c|}{ Time } & \multirow[b]{2}{*}{$\mathrm{p}$} \\
\hline & Extubation & 15-min & 30-min. & 45-min & 60-min. & $6-h$ & $12-\mathrm{h}$ & 24-h & 48-h & \\
\hline \multirow[t]{2}{*}{$\mathrm{SpO}_{2}$} & $92.5 \pm 1.4$ & $93.9 \pm 1.2$ & $95.2 \pm 1.1$ & $95 \pm 0.9$ & $95 \pm 0.2$ & $97 \pm 1.3$ & $98 \pm 0.6$ & $98 \pm 0.4$ & $98 \pm 0.8$ & 0.02 \\
\hline & $94.1 \pm 0.8$ & $94 \pm 0.9$ & $94.08 \pm 0.3$ & $94 \pm 0.8$ & $94 \pm 0.7$ & $94 \pm 0.7$ & $94 \pm 1.2$ & $93 \pm 1.1$ & $93 \pm 2.6$ & 0.06 \\
\hline $\mathrm{p}^{*}$ & 0.51 & 0.43 & 0.08 & 0.09 & 0.03 & 0.02 & $<0.01$ & $<0.01$ & 0.001 & \\
\hline \multirow[t]{2}{*}{ SF } & $237 \pm 8$ & $254 \pm 6.2$ & $263 \pm 6.4$ & $274 \pm 7$ & $285 \pm 7$ & $290 \pm 6.7$ & $301 \pm 7.1$ & $316 \pm 7.9$ & $335 \pm 7.4$ & $<0.001$ \\
\hline & $260 \pm 8$ & $251 \pm 6.2$ & $249 \pm 6.4$ & $245 \pm 7$ & $242 \pm 7$ & $238 \pm 6.7$ & $234 \pm 7.1$ & $231 \pm 8$ & $232 \pm 7.6$ & 0.009 \\
\hline $\mathrm{p}^{*}$ & 0.40 & 0.784 & 0.122 & 0.005 & 0.001 & 0.001 & 0.001 & 0.001 & 0.001 & \\
\hline \multirow{2}{*}{$\begin{array}{l}\mathrm{PCO}_{2} \\
(\mathrm{~mm} \mathrm{Hg})\end{array}$} & $36.4 \pm 1.16$ & & $37.5 \pm 1.12$ & & $37.4 \pm 1.14$ & $36.7 \pm 1.13$ & $36.9 \pm 1.2$ & $36.2 \pm 1.2$ & $37.3 \pm 1.13$ & 0.300 \\
\hline & $38.8 \pm 1.15$ & & $39.1 \pm 1.12$ & & $40 \pm 1.14$ & $39.9 \pm 1.13$ & $39.7 \pm 1.21$ & $41 \pm 1.27$ & $40.5 \pm 1.19$ & 0.357 \\
\hline $\mathrm{p}^{*}$ & 0.142 & & 0.290 & & 0.103 & 0.051 & 0.105 & 0.008 & 0.063 & \\
\hline \multirow{2}{*}{$\begin{array}{l}\mathrm{EtCO}_{2} \\
(\mathrm{~mm} \mathrm{Hg})\end{array}$} & $35.2 \pm 8$ & $36.3 \pm 6.2$ & $37.3 \pm 6.4$ & $36.6 \pm 7$ & $36 \pm 7$ & $36.3 \pm 6.7$ & $36.1 \pm 7.1$ & $35.3 \pm 7.9$ & $36.3 \pm 7.4$ & 0.018 \\
\hline & $37.4 \pm 8$ & $37.6 \pm 6.2$ & $37.7 \pm 6.4$ & $37.8 \pm 7$ & $38.6 \pm 7$ & $38.3 \pm 6.7$ & $38.3 \pm 7.1$ & $39.3 \pm 8$ & $39.1 \pm 7.6$ & 0.391 \\
\hline $\mathrm{p}^{*}$ & 0.165 & 0.389 & 0.813 & 0.447 & 0.095 & 0.210 & 0.163 & 0.018 & 0.126 & \\
\hline \multirow[t]{2}{*}{$\mathrm{RR}(/ \min )$} & $35.4 \pm 1.8$ & $35.3 \pm 1.7$ & $34.7 \pm 1.7$ & $34.4 \pm 1.7$ & $34 \pm 1.8$ & $34.1 \pm 1.8$ & $32.9 \pm 1.7$ & $32.7 \pm 1.7$ & $32 \pm 1.8$ & 0.048 \\
\hline & $40.7 \pm 1.8$ & $41 \pm 1.7$ & $41 \pm 1.7$ & $41 \pm 1.6$ & $41.7 \pm 1.8$ & $43 \pm 1.8$ & $42.5 \pm 1.7$ & $43 \pm 1.8$ & $43.6 \pm 1.8$ & 0.340 \\
\hline $\mathrm{p}^{*}$ & 0.04 & 0.023 & 0.009 & 0.006 & 0.003 & 0.001 & 0.001 & 0.001 & 0.001 & \\
\hline \multirow[t]{2}{*}{$\operatorname{HR}(/ \min )$} & $134.8 \pm 3$ & $138.8 \pm 3$ & $132.2 \pm 4$ & $131 \pm 3$ & $129 \pm 3$ & $127 \pm 3$ & $124 \pm 3$ & $126 \pm 3$ & $124 \pm 3$ & 0.001 \\
\hline & $132 \pm 3$ & $138 \pm 3$ & $132 \pm 3$ & $131 \pm 3$ & $133 \pm 3$ & $131 \pm 3$ & $130 \pm 3$ & $132 \pm 3$ & $134 \pm 3$ & 0.103 \\
\hline $\mathrm{p}^{*}$ & 0.535 & 0.952 & 0.308 & 0.685 & 0.354 & 0.298 & 0.047 & 0.111 & 0.01 & \\
\hline \multirow{2}{*}{$\begin{array}{l}\text { SBP } \\
(\mathrm{mm} \mathrm{Hg})\end{array}$} & $99.2 \pm 2.5$ & $99.6 \pm 2.5$ & $96.7 \pm 2.9$ & $97.9 \pm 2.4$ & $98.7 \pm 2.4$ & $99.7 \pm 2.4$ & $98.1 \pm 2.5$ & $99.9 \pm 2.6$ & $96.5 \pm 2.7$ & 0.058 \\
\hline & $95.8 \pm 2.6$ & $95.2 \pm 2.5$ & $96.3 \pm 2.9$ & $94.5 \pm 2.4$ & $94.2 \pm 2.4$ & $95.4 \pm 2.4$ & $95 \pm 2.6$ & $93.4 \pm 2.7$ & $95.7 \pm 2.7$ & 0.340 \\
\hline $\mathrm{p}^{*}$ & 0.341 & 0.218 & 0.910 & 0.333 & 0.190 & 0.211 & 0.358 & 0.085 & 0.828 & \\
\hline \multirow{2}{*}{$\begin{array}{l}\mathrm{DBP} \\
(\mathrm{mm} \mathrm{Hg})\end{array}$} & $59.7 \pm 1.7$ & $61 \pm 1.6$ & $61.7 \pm 1.5$ & $60.7 \pm 1.6$ & $62 \pm 1.5$ & $63 \pm 1.4$ & $61 \pm 1.4$ & $62.5 \pm 1.6$ & $60.8 \pm 1.8$ & 0.302 \\
\hline & $59.4 \pm 1.7$ & $60.3 \pm 1.6$ & $61 \pm 1.5$ & $60.4 \pm 1.6$ & $60.3 \pm 1.5$ & $60.1 \pm 1.4$ & $59.6 \pm 1.4$ & $59.6 \pm 1.7$ & $61 \pm 1.9$ & 0.943 \\
\hline $\mathrm{p}^{*}$ & 0.876 & 0.747 & 0.722 & 0.878 & 0.455 & 0.141 & 0.408 & 0.215 & 0.973 & \\
\hline
\end{tabular}

First and second row indicate HFNC and COT groups for each variable, respectively.

COT: conventional oxygen therapy; DBP: diastolic blood pressure; HFNC: high-flow nasal oxygen cannula;

HR: heart rate; RR: respiratory rate; SBP: systolic blood pressure; SF: $\mathrm{SpO}_{2} / \mathrm{FiO}_{2}$

$\mathrm{p}$ : intragroup comparison, $\mathrm{p}^{*}$ : intergroup comparison. 
$(\mathrm{p}=0.001)$; and was lower in HFNC group at 12 and 48 hours, compared to COT group $(\mathrm{p}=0.047$ and $\mathrm{p}=0.01$, respectively). Systolic and diastolic blood pressure levels did not change during the immediate-extubation period in both groups. Comprehensive analyses of clinical and laboratory parameters for the two groups were presented in Table II.

The initial m-RAS was higher in the HFNC group, compared to COT group (1.391 \pm 0.9 vs. $0.997 \pm 0.09, \mathrm{p}=0.003)$. At follow-up m-RAS decreased steadily in the HFNC group; and at 48 hours it was significantly lower in the HFNC group, compared to the COT group $(p=0.001)$. Changes of $m-R A S$ were presented in Table III.

\section{Secondary outcomes}

After the extubation, 11 patients $(22 \%)$ in the COT and 2 patients (4\%) in the HFNC group, were reintubated. Hypoxia or oxygen desaturation, hypercapnia with respiratory acidosis, decreased level of consciousness, and inability to clear secretions occurred in 4,3 , 2 , and 4 patients, respectively. The incidence of reintubation was statistically lower in the HFNC group $(p=0.007)$. The median reintubation time was 16 hours (10-24 hours) in HFNC group; and 12 hours (6-24 hours) in COT group $(\mathrm{p}=0.066)$.

\section{Discussion}

Administration of oxygen via nasal cannula and face mask is a traditional method used for hypoxemic respiratory failure after extubation period. ${ }^{6,14,15}$ However, inadequate heating and inadequate humidification leads to dry nose, dry throat and nasal pain and ultimately to extubation failure. ${ }^{16}$ Reintubation due to extubation failure is associated with increased risk for infection, lung and airway injury, length of stay, and sedation-related complications with related high costs. ${ }^{17}$ During this period noninvasive mechanical ventilation (NIV) may be an alternative method to ameliorate respiratory failure and reintubation. ${ }^{18,19}$ This method requires a different type of mask and different sedation to deliver adequate ventilation. Two studies comparing NIV to COT in critically ill patients at high risk of reintubation found that NIV was more effective. ${ }^{20,21}$ However, $3-20 \%$ of patients require reintubation during NIV treatment. $8,18,22$ Compared with NIV, HFNC is a newer noninvasive treatment method for respiratory failure. Under normal breathing conditions $30 \%$ of the tidal volume inhaled is anatomical dead space. At the beginning of inhalation, this dead space is filled with the gas remaining from the previous breath. HFNC systems may improve breathing efficiency by flooding the nasopharyngeal dead space with clean gas, thereby improving the minute ventilation. In this way the treatment provides better alveolar gas fractions and carbon dioxide elimination. Appropriate humidification and heating via HFNC reduce the work required for breathing and recovery of the respiratory pattern, heart rate and other factors. ${ }^{23}$ However, like any respiratory system, this device has drawbacks. The noise level reaches approximately 80 $\mathrm{dB}$, which is correlated with the flow and may be higher than that generated by other CPAP systems. The risk of air leak syndrome (pneumothorax, pneumomediastinum) could be associated with an inappropriate prong size that occludes the nostril lumen. ${ }^{24} \mathrm{We}$ did not encounter any problems regarding the use of HFNC. HFNC has been reported mostly for pediatric patients especially during the neonatal period and has shown many benefits. ${ }^{4,25,26}$ To our knowledge this is the most comprehensive study evaluating the influence of HFNC and COT on extubation success

Table III. Changes of m-RAS After Extubation Period.

\begin{tabular}{lcccc}
\hline \multirow{2}{*}{ Groups } & \multicolumn{4}{c}{ Time } \\
\cline { 2 - 5 } & Extubation & $24-\mathrm{h}$ & $48-\mathrm{h}$ & $\mathrm{p}$ \\
\hline HFNC & $1.391 \pm 0.9$ & $1.221 \pm 0.17$ & $0.607 \pm 0.1$ & 0.001 \\
COT & $0.997 \pm 0.09$ & $1.164 \pm 0.19$ & $1.451 \pm 0.108$ & 0.002 \\
$\mathrm{p}^{*}$ & 0.003 & 0.824 & 0.001 & \\
\hline
\end{tabular}

COT: conventional oxygen therapy; HFNC: high-flow nasal oxygen cannula; m-RAS: modified radiological atelectasis score. $\mathrm{p}$ : intragroup comparison, $\mathrm{p}^{*}$ : intergroup comparison 
associated with respiratory hemodynamic and radiologic parameters in a large pediatric population. We analyzed respiratory parameters including $\mathrm{SpO}_{2}, \mathrm{PCO}_{2}, \mathrm{EtCO}_{2}$, SF ratio and respiratory rate. SF ratio is one of the most important respiratory parameters. Using SF ratio, we standardized the degree of hypoxemia which had different $\mathrm{SpO}_{2}$ and $\mathrm{FiO}_{2}$ in children without extra blood samples. The SF ratio has been especially useful for quantifying the $\mathrm{PaO}_{2} /$ $\mathrm{FiO}_{2}$ ratio of hypoxemia in pediatric and adult patients ${ }^{27,28}$ We observed an increase in $\mathrm{SPO}_{2}$ during the first 60 minutes and in the SF ratio during the first 45 minutes from the baseline values in the HFNC group. As compared with $\mathrm{SpO}_{2}$, the SF ratio may be an early predictor of respiratory failure.

Respiratory rate and $\mathrm{EtCO}_{2}$ levels decreased during follow-up in the HFNC group but there was no difference in $\mathrm{PCO}_{2}$ levels in both groups. A new study reported better values in $\mathrm{SpO}_{2}$ levels and no difference in $\mathrm{PaO}_{2} / \mathrm{FiO}_{2}$ with HFNC therapy after extubation. ${ }^{5}$ The authors also detected decreased respiratory rates, and $\mathrm{PCO}_{2}$ levels after extubation for the HFNC group as compared with noninvasive ventilation group. Similar to our study, Brotfain et al. ${ }^{29}$ reported a better oxygenation with HFNC but $\mathrm{PaCO}_{2}$ and respiratory rate were not different between the two groups. In a study by Testa et al. ${ }^{8}$ they reported that HFNC had no impact on $\mathrm{PaCO}_{2}$ in a series of 89 pediatric cardiac surgery patients. We also monitored $\mathrm{EtCO}_{2}$ levels to evaluate the changes in respiratory status. $\mathrm{EtCO}_{2}$ also provides additional information about cardiac performance and metabolic status. ${ }^{30}$ Despite a good correlation between $\mathrm{PCO}_{2}$ levels and $\mathrm{EtCO}_{2}$ levels, EtCO 2 levels changed significantly only in the HFNC group. We considered this result attributable to leakage from the cannula, the influence of different flow rates and anatomical dead space. In our study, consistent with HFNC mechanisms, the response to hypoxemia was observed in an earlier period than the response to hypercapnia.

When we considered heart rate, noninvasive systolic blood pressure and diastolic pressure, heart rate decreased only in the HFNC group. There was no difference between the two groups in terms of systolic and diastolic blood pressure. Rittayamai et al. $^{6}$ reported similar results to our study; but conversely, there was no significant change in heart rate and blood pressure in the study by Tiruvoipati et al. ${ }^{31}$

Unlike the other studies, we also evaluated m-RAS in this study. In a study assessing atelectasis using chest radiograph after cardiac surgery, the m-RAS provided more detailed information about atelectasis and oxygenation requirements during follow-up ${ }^{13}$. We observed higher m-RAS for the HFNC group at the beginning, m-RAS decreased steadily in the HFNC group at 48 hours and were significantly lower than those of the COT group at follow-up. Ensuring adequate oxygenation and respiratory support is vital after extubation to prevent atelectasis; however, there is little evidence to guide clinicians in the objective selection and use of oxygen delivery devices. ${ }^{13,32}$ HFNC systems also supply a certain degree of distending pressure for alveolar recruitment and prevent atelectasis. This pressure is variable (approximately 4-8 $\mathrm{cm} \mathrm{H}_{2} \mathrm{O}$ ) and related to nasal prong size, leaks and open mouth and the effectiveness of the humidity and heat. ${ }^{26,33}$ During follow-up, we considered that lower m-RAS score was associated with improved pulmonary function and reduced atelectasis for the HFNC group.

Additionally, 13 patients were reintubated at follow-up. All patients required invasive mechanical ventilation in our study. Similar to NIV strategy, the greatest risk in using HFNC is that it may delay the recourse the mechanical ventilation. In children the risk of HFNC failure, defined as intubation requirement, ranges from $8 \%$ to $19 \% .{ }^{33}$ The incidence of reintubation was significantly lower for the HFNC group (4\%) than for the COT group (22\%). Testa et al. ${ }^{8}$ reported that the incidence of treatment failure was $15 \%$ and two pediatric cardiac surgical patients were reintubated (1 patient in the HFNC group and 1 patient in the COT group). There was also no difference between the two groups regarding incidence of reintubation in this study. ${ }^{8}$ However, a randomized controlled trial comparing the effects of the venturi mask and HFNC therapy showed less required reintubation following extubation in the HFNC group. It is estimated that a better lung compliance, decreased patient effort and improved secretion clearance may have played a role. ${ }^{34}$

Our study has several limitations. First, we 
compared the effects of COT and HFNC therapy in nonhomogeneous group. Second, since HFNC system is more expensive than COT (HFNC costs approximately 114 USD per patient and is not included in intensive care payment system. During the study, COT was approximately 4.20 USD in our country.), the clinical application of HFNC may be advised for selected patients in PICU. As the third, we also titrated the flow rate according to patient's respiratory distress but we had no opportunity to measure subsequent changes in generated pressure.

In conclusion, HFNC is better than COT, especially for the restoration of the respiratory and radiologic parameters. Although more expensive, the use of HFNC may have more advantages to reduce the risk of extubation failure in critically ill children compared with COT.

\section{Acknowledgments}

This study was supported by Erciyes University Scientific Research Center (TTU-2014-5333).

\section{REFERENCES}

1. Kernick J, Magarey J. What is the evidence for the use of high flow nasal cannula oxygen in adult patients admitted to critical care units? A systematic review. Aust Crit Care 2010; 23: 53-70.

2. Mayfield S, Jauncey-Cooke J, Bogossian F. A case series of paediatric high flow nasal cannula therapy. Aust Crit Care 2013; 26: 189-192.

3. Chatila W, Nugent T, Vance G, Gaughan J, Criner GJ. The effects of high-flow vs low-flow oxygen on exercise in advanced obstructive airways disease. Chest 2004; 126: $1108-1115$.

4. Lee JH, Rehder KJ, Williford L, Cheifetz IM, Turner DA. Use of high flow nasal cannula in critically ill infants, children, and adults: a critical review of the literature. Intensive Care Med 2013; 39: 247-257.

5. Yoo JW, Synn A, Huh JW, Hong SB, Koh Y, Lim CM. Clinical efficacy of high-flow nasal cannula compared to noninvasive ventilation in patients with post-extubation respiratory failure. The Korean J Intern Med 2016; 31: 82-88.

6. Rittayamai N, Tscheikuna J, Rujiwit P. High-flow nasal cannula versus conventional oxygen therapy after endotracheal extubation: a randomized crossover physiologic study. Respiratory Care 2014; 59: 485-490.

7. Manley BJ, Owen L, Doyle LW, Davis PG. High-flow nasal cannulae and nasal continuous positive airway pressure use in non-tertiary special care nurseries in Australia and New Zealand. J Paediatr Child Health 2012; 48: 16-21.
8. Testa G, Iodice F, Ricci Zi, et al. Comparative evaluation of high-flow nasal cannula and conventional oxygen therapy in paediatric cardiac surgical patients: a randomized controlled trial. Interact Cardiovasc Thorac Surg 2014; 19: 456-461.

9. Hernandez G, Vaquero C, Collinas L, Cuena R, Gonzales P, Canabal A. Effect of postextubation high-flow nasal cannula vs noninvasive ventilation on reintubation and post extubation respiratory failure in high-risk patients: a randomized controlled trial. JAMA 2016; 316: 1565-1574.

10. Shapiro BA, Harrison RA, Kacmarek RM, Cane RA. Clinical Application of Respiratory Care (3rd ed). Chicago, IL: Year Book Medical Publishers, 1985: 180-187.

11. Newth CJ, Venkataraman S, Willson DF. Weaning and extubation readiness in pediatric patients. Pediatr Crit Care Med 2009; 10: 1-11.

12. Ferguson LP, Walsh BK, Munhall D, Arnold JH. A spontaneous breathing trial with pressure support overestimates readiness for extubation in children. Pediatr Crit Care Med 2011: 12: 330-335.

13. Parke RL, McGuinness SP, Milne D, Jull A. A new system for assessing atelectasis on chest $\mathrm{x}$-ray after sternotomy for cardiac surgery. Med Imaging Radiol 2014; 2: 2 .

14. Epstein SK, Ciubotaru RL, Wong JB. Effect of failed extubation on the outcome of mechanical ventilation. Chest 1997; 112: 186-192.

15. L'Her E, Deye N, Lellouche F, Taille S, Demoule A, Fraticelli A. Physiologic effects of noninvasive ventilation during acute lung injury. Am J Respir Crit Care Med 2005; 172: 1112-1118.

16. Nishimura M. High-flow nasal cannula oxygen therapy in adults. J Intensive Care 2015; 3: 1-8.

17. Coletti K, Bagdure DN, Walker LK, Remy KE, Custer JW. High-flow nasal cannula utilization in pediatric critical care. Respir Care 2017; 62: 1-7.

18. Nava S, Gregoretti C, Fanfulla F, et al. Noninvasive ventilation to prevent respiratory failure after extubation in high-risk patients. Crit Care Med 2005; 33: 24652470.

19. Murase K, Chihara Y, Takahashi K, et al. Use of noninvasive ventilation for pediatric patients after liver transplantation: Decrease in the need for reintubation. Liver Transpl 2012; 18: 1217-1225.

20. Ferrer M, Valencia M, Nicolas JM, Bernadich O, Badia JR, Torres A. Early noninvasive ventilation averts extubation failure in patients at risk: A randomized trial. Am J Respir Crit Care Med 2006; 173: 164-170.

21. Nava S, Gregoretti C, Fanfulla F, et al. Noninvasive ventilation to prevent respiratory failure after extubation in high-risk patients. Crit Care Med 2005; 33: 24652470.

22. Epstein SK, Ciubotaru RL. Independent effects of etiology of failure and time to reintubation on outcome for patients failing extubation. Am J Respir Crit Care Med 1998; 158: 489-493. 
23. Medina A, Pons-Odena M, Torres-Martinon F. Noninvasive Ventilation in Pediatrics ( $3^{\text {rd }}$ ed). Barcelona: Ergon; 2015: 82-89.

24. Milesi C, Boubal M, Jacquot A, et al. High-flow nasal cannula : Recommendations for daily practice in pediatrics. Ann Intensive Care 2014; 4: 1-7.

25. Holleman-Duray D, Kaupie D, Weiss MG. Heated humidified high-flow nasal cannula: Use and a neonatal early extubation protocol. J Perinatol 2007; 27: 776781.

26. El-Khatib MF. High-flow nasal cannula oxygen therapy during hypoxemic respiratory failure. Respir Care 2012; 57: 1696-1698.

27. Mayordomo-Colunga J, Pons M, Lopez Y, et al. Predicting non-invasive ventilation failure in children from the $\mathrm{SpO}_{2} / \mathrm{FiO}_{2}$ (SF) ratio. Intensive Care Med 2013; 39: 1095-1103.

28. Khemani RG, Patel NR, Bart RD 3rd, Newth CJL. Comparison of the pulse oximetric saturation/fraction of inspired oxygen ratio and the $\mathrm{PaO}_{2} /$ fraction of inspired oxygen ratio in children. Chest 2009; 135 : 662-668.
29. Brotfain E, Zlotnik A, Schwartz A, et al. Comparison of the effectiveness of high flow nasal oxygen cannula vs. standard non-rebreather oxygen face mask in postextubation intensive care unit patients. The Isr Med Assoc J 2014; 16: 718-722

30. Krauss B. Advances in the use of capnography for nonintubated patients. Isr J Emerg Med 2008; 8: 3-15

31. Tiruvoipati R, Lewis D, Haji K, Botha J. High-flow nasal oxygen vs high-flow face mask: A randomized crossover trial in extubated patients. J Crit Care 2010; 25: 463-468.

32. Eastwood GM, O'Connell B, Considine J. Oxygen delivery to patients after cardiac surgery: A medical record audit. Crit Care Resusc 2009; 11: 238-243

33. Brink F, Duke T, Evans J. High-flow nasal prong oxygen therapy or nasopharyngeal continuous positive airway pressure for children with moderate-to-severe respiratory distress? Pediatr Crit Care Med 2013; 14: 326-331.

34. Maggiore SM, Idone FA, Vaschetto R, et al. Nasal high-flow versus Venturi mask oxygen therapy after extubation. Effects on oxygenation, comfort, and clinical outcome. Am J Respir Crit Care Med 2014; 190: 282-288. 